\title{
Reduction of arcuate kappa-opioid receptor-expressing cells increased luteinizing hormone pulse frequency in female rats
}

\author{
Mingdao Dai ${ }^{1)}$, Sho Nakamura ${ }^{1)}$, Chudai Takahashi ${ }^{1)}$, Marimo Sato ${ }^{1)}$, Arisa Munetomo ${ }^{1)}$, Fumie Magata ${ }^{1)}$, \\ Yoshihisa Uenoyama ${ }^{2)}$, Hiroko Tsukamura ${ }^{2)}$ and Fuko Matsuda ${ }^{1)}$ \\ 1) Laboratory of Theriogenology, Department of Veterinary Medical Sciences, The University of Tokyo, Tokyo 113-8657, Japan \\ 2) Laboratory of Animal Reproduction, Graduate School of Bioagricultural Sciences, Nagoya University, Nagoya 464-8601, Japan
}

\begin{abstract}
The brain mechanism responsible for the pulsatile secretion of gonadotropin-releasing hormone $(\mathrm{GnRH})$ is important for maintaining reproductive function in mammals. Accumulating evidence suggests that kisspeptin/neurokinin B/ dynorphin A (KNDy) neurons in the hypothalamic arcuate nucleus (ARC) play a critical role in the regulation of pulsatile GnRH and subsequent gonadotropin secretion. Dynorphin A (Dyn) and its receptor, kappa-opioid receptor (KOR, encoded by Oprk1), have been shown to be involved in the suppression of pulsatile $\mathrm{GnRH} /$ luteinizing hormone (LH) release. On the other hand, it is still unclear whether the inhibitory Dyn signaling affects KNDy neurons or KOR-expressing non-KNDy cells in the ARC or other brain regions. We therefore aimed to clarify the role of ARC-specific Dyn-KOR signaling in the regulation of pulsatile GnRH/LH release by the ARC specific cell deletion of KOR-expressing cells using Dyn-conjugated-saporin (DynSAP). Estrogen-primed ovariectomized female rats were administered Dyn-SAP to the ARC. In situ hybridization of Oprk1 showed that ARC Dyn-SAP administration significantly decreased the number of Oprkl-expressing cells in the ARC, but not in the ventromedial hypothalamic nucleus and paraventricular nucleus. The frequency of LH pulses significantly increased in animals bearing the ARC Dyn-SAP administration. The number of Kiss l-expressing cells in the ARC was not affected by ARC Dyn-SAP treatment. Dyn-KOR signaling within the ARC seems to mediate the suppression of the frequency of pulsatile GnRH/LH release, and ARC non-KNDy KOR neurons may be involved in the mechanism modulating GnRH/LH pulse generation.
\end{abstract}

Key words: Luteinizing hormone pulse, Kappa-opioid receptor, Saporin, Kisspeptin/neurokinin B/dynorphin A neuron, Dynorphin

THE BRAIN MECHANISM responsible for the pulsatile secretion of gonadotropin-releasing hormone $(\mathrm{GnRH})$, which stimulates gonadotropin release and consequent follicular development/steroidogenesis, is of deep significance because GnRH induces gonadotropin release only when GnRH is secreted in a pulsatile manner at a physiological frequency in mammals $[1,2]$. The mechanism generating pulsatile GnRH secretion is called the GnRH pulse generator, and its activity is suggested to be modulated by steroid feedback actions and various environmental factors, such as nutritional status, stress, and suckling stimulus. Kisspeptin (first named metastin) was

Submitted Dec. 29, 2020; Accepted Mar. 8, 2021 as EJ20-0832

Released online in J-STAGE as advance publication Apr. 17, 2021 Correspondence to: Fuko Matsuda, Ph.D., DVM, Laboratory of Theriogenology, Department of Veterinary Medical Sciences, The University of Tokyo, 1-1-1 Yayoi, Bunkyo-ku, Tokyo 113-8657, Japan.

E-mail: afukomat@g.ecc.u-tokyo.ac.jp identified as an endogenous ligand for GPR54 [3], and accumulating evidence suggests that kisspeptin-GPR54 signaling controls reproductive function via the stimulation of GnRH/gonadotropin release in several mammalian species, such as rodents [4-7], ruminants [8-12], and primates [13-15]. Loss of function studies of kisspeptin or GPR54 by genetic mutation or conventional knockout showed hypogonadotropic hypogonadism with low to undetectable luteinizing hormone (LH) levels, which clearly demonstrates that kisspeptin-GPR54 signaling is a fundamental factor for stimulating $\mathrm{GnRH} / \mathrm{LH}$ secretion in rodents and humans [16-18]. Kisspeptin neurons located in the hypothalamic arcuate nucleus (ARC) coexpress neurokinin $\mathrm{B}(\mathrm{NKB})$ and dynorphin A (Dyn) in rats [19-21], mice [22], guinea pigs [23], sheep [24], and goats [25], and are therefore referred to as KNDy neurons [9], and suggested to be the GnRH/LH pulse generator [25-31].

Dyn and its receptor, kappa-opioid receptor (KOR, 
encoded by Oprk1), have been suggested to be involved in the suppression of frequency and/or baseline of pulsatile GnRH/LH release because the frequency of LH pulses was reduced by intracerebroventricular Dyn administration and increased by central administration of nor-binaltorphimine (nor-BNI), a KOR antagonist, in ovariectomized goats [25] and nor-BNI administration increased the baseline level of LH pulses without affecting LH pulse frequencies in estrogen-primed female rats [32]. Dyn neurons are abundantly located in the hypothalamus, including the paraventricular nucleus (PVN) as well as the ARC [33, 34]. Our recent study suggested that PVN Dyn neurons mediate glucoprivic GnRH/LH pulse suppression, since central administration of norBNI blocked LH pulse suppression induced by the peripheral or central administration of 2-deoxy-Dglucose (2DG), a glucose utilization inhibitor, and the 2DG administration activated PVN Dyn neurons [35]. These studies demonstrate that Dyn-KOR signaling negatively controls pulsatile GnRH/LH secretion under normal or glucoprivic conditions. On the other hand, it is still unclear whether inhibitory Dyn signaling affects KOR-expressing cells in the ARC and/or other brain regions to control the frequency and/or baseline of $\mathrm{GnRH} / \mathrm{LH}$ pulses because KOR is widely distributed in the brain, including the hypothalamus, telencephalon (amygdala, claustrum, endopiriform nucleus, etc.), and mesencephalon (periaqueductal gray, substantia nigra, etc.) $[36,37]$.

KOR-expressing cells are reported to be distributed in the hypothalamus, including the ARC, PVN, and ventromedial hypothalamic nucleus (VMH) $[37,38]$. An in vitro study by De Croft et al. [39] demonstrated that Dyn treatment reduced the firing rate of ARC kisspeptin neurons via $\mathrm{KOR}$ in mouse brain slices. Oprk1-expressing cells were widely observed in the ARC, and some of those cells were KNDy neurons in mice $[22,40]$ and rats [35]. These findings suggest that Dyn-KOR signaling in the ARC is involved in $\mathrm{GnRH} / \mathrm{LH}$ pulse generation by directly acting on KNDy neurons. On the other hand, another study showed that KOR immunoreactivities were also found in Kiss 1 -negative cells in the ARC as well as GnRH neurons in the preoptic area (POA) in female rats [38], suggesting that Dyn may affect ARC non-KNDy KOR-expressing cells and/or GnRH neurons in the rat. To further understand the role of Dyn-KOR signaling in the regulation of $\mathrm{GnRH} / \mathrm{LH}$ pulse generation, it is worth clarifying the role of ARC-specific Dyn-KOR signaling in the regulation of pulsatile $\mathrm{GnRH} / \mathrm{LH}$ release and examining whether the KOR-expressing cells involved in pulse generation are KNDy neurons and/or non-KNDy neurons.

The present study aimed to clarify the role of ARC
Dyn-KOR signaling in GnRH/LH pulse generation. For this purpose, we administered Dyn-conjugated-saporin (Dyn-SAP), which specifically causes cell death in KOR-expressing cells, into the ARC of adult female rats. The effect of the administration on the number of Oprk1expressing cells in the ARC, PVN, and VMH was examined to confirm whether Dyn-SAP causes ARC-specific attenuation of KOR-expressing cells. Animals administered with Dyn-SAP into the ARC were subjected to frequent blood sampling to detect LH pulses as a marker of GnRH pulses to examine the effects of ARC-specific attenuation of KOR-expressing cells on the frequency and baseline of pulsatile LH secretion. Further, the effect of intra-ARC Dyn-SAP treatment on the number of kisspeptin gene (Kiss1)-expressing cells in the ARC of female rats was examined to determine if KORexpressing cells deleted by the current Dyn-SAP treatment were KNDy or non-KNDy neurons.

\section{Materials and Methods}

\section{Animals}

Adult Wistar-Imamichi strain female rats (8-weeks old at the time of brain surgery, 11-weeks old, 200-250 g at the time of blood sampling; Institute for Animal Reproduction, Kasumigaura, Japan) were individually housed in a temperature $\left(22 \pm 2{ }^{\circ} \mathrm{C}\right)$ and humidity $(40 \%-60 \%)$ controlled room in The University of Tokyo with a 14-h light and 10-h dark condition (lights on at $0500 \mathrm{~h}$ ) and $\mathrm{ad}$ libitum access to water and food (CE-2; Clea Japan Inc., Tokyo, Japan). Animals showing at least two normal estrous cycles confirmed by observation of their vaginal smear were subjected to brain surgeries under isoflurane anesthesia. All protocols were conducted in accordance with the Guidelines for the Care and Use of Laboratory Animals, Graduate School of Agricultural and Life Sciences, The University of Tokyo.

\section{Stereotaxic injection of Dyn-SAP into the ARC and frequent blood sampling}

We used Dyn-SAP (Advanced Targeting Systems, San Diego, CA, USA) to determine the effect of deletion of KOR-expressing cells in the ARC on GnRH/LH pulse. Saporin (SAP) is a ribosome-inactivating protein that can induce cell death by preventing protein synthesis [41]. SAP itself is a non-toxic molecule when it exists extracellularly, while a composite of SAP conjugated to a specific ligand can enter cells via specific receptors for the ligand, and consequently induce cell death. Female rats were stereotaxically injected with Dyn-SAP $(n=7)$ or SAP $(n=6)$ as a control bilaterally into the anterior and posterior ARC (totally 4 injection sites) according to the rat brain atlas [42] as follows: $2.5 \mathrm{~mm}$ posterior and 
$\pm 0.5 \mathrm{~mm}$ lateral to the bregma and $9.8 \mathrm{~mm}$ ventral to skull surface for the anterior ARC; $3.6 \mathrm{~mm}$ posterior and $\pm 0.5 \mathrm{~mm}$ lateral to the bregma and $10.1 \mathrm{~mm}$ ventral to skull surface for the posterior ARC. Dyn-SAP $(20 \mathrm{ng} / 200 \mathrm{~nL})$ or SAP $(18.6 \mathrm{ng} / 200 \mathrm{~nL})$ dissolved in PBS was slowly infused at a rate of $100 \mathrm{~nL} / \mathrm{min}$ into each injection site. After infusion, the injector was kept in place for an additional $5 \mathrm{~min}$ for adequate reagent diffusion. The amounts and the position of Dyn-SAP injection were determined according to a previous report using another ligand-conjugated saporin targeting the ARC [43].

Two weeks after the brain surgery for Dyn-SAP/SAP injection, rats were bilaterally ovariectomized (OVX) and implanted with a silicone tubing (i.d., $1.57 \mathrm{~mm}$; o.d., $3.18 \mathrm{~mm} ; 25 \mathrm{~mm}$ in length; Dow Corning, Midland, MI, USA) filled with estradiol ( $\mathrm{E}_{2}$; Sigma-Aldrich, St. Louis, MO) dissolved in peanut oil (Sigma-Aldrich) at $20 \mu \mathrm{g} / \mathrm{mL}$ to serve as diestrus model [44]. Six days after the OVX, a silicone tubing (i.d., $0.5 \mathrm{~mm}$; o.d., $1.0 \mathrm{~mm}$; Shin-Etsu Polymer Co., Tokyo, Japan) for blood sampling was inserted into the right atrium of rats through the jugular vein. On the next day, three weeks after brain surgery, $100 \mu \mathrm{L}$ of blood was collected every 6 min for $3 \mathrm{~h}$ from $1300 \mathrm{~h}$ from free-moving conscious rats to detect pulsatile LH release. An equivalent volume of rat red blood cells prepared with heparinized saline was replaced through the same atrial cannula after each blood collection to keep the hematocrit level constant. Plasma samples were separated by centrifugation $\left(15,300 \mathrm{~g}, 20 \mathrm{~min}, 4^{\circ} \mathrm{C}\right)$ and stored at $-20^{\circ} \mathrm{C}$ until LH assay.

\section{Histological analysis}

Rats were transcardially perfused with $4 \%$ paraformaldehyde under deep anesthesia with sodium pentobarbital for brain sampling on the same day after frequent blood sampling. Brains were collected and post-fixed in the same fixative overnight at $4^{\circ} \mathrm{C}$, and then immersed in $30 \%$ sucrose in phosphate buffer for $48 \mathrm{~h}$ at $4^{\circ} \mathrm{C}$ before sectioning. Serial coronal brain sections of $50 \mu \mathrm{m}$ thickness were obtained using a cryostat. Every fourth section was stained with thionin solution to verify the injection placement in the ARC by microscopic inspection (DM 2500, Leica Microsystems, Wetzlar, Germany).

Another series of every fourth brain section was subjected to free-floating in situ hybridization (ISH) of Oprk1 or Kiss1. Oprk1 mRNA was detected by ISH using the digoxigenin (DIG)-labeled antisense cRNA probe, synthesized by in vitro transcription from rat hypothalamic complementary DNA using a DIG RNA labeling kit (Roche Diagnostics, Basel, Switzerland) as described in a previous study [45], aiming at position
264-1404 of NM 017167. After hybridized with the cRNA probe for $16 \mathrm{~h}$ at $60^{\circ} \mathrm{C}$, sections were incubated with anti-DIG antibody conjugated to alkaline phosphatase $(1: 1,000$, Roche Diagnostics) for another $16 \mathrm{~h}$ at room temperature. The signal was visualized using 4-nitroblue tetrazolium chloride/5-bromo-4-chloro-3indoyl-phosphate (NBT/BCIP, Roche Diagnostics). The sections were sealed with Entellan New Rapid Mounting Medium (Merck, Darmstadt, Germany). For Kiss 1 ISH, a fluorescein isothiocyanate (FITC)-labeled Kiss 1 probe (33-348 of NM_181692), synthesized by a FITClabeling kit (Roche Diagnostics), was hybridized for $16 \mathrm{~h}$ at $60^{\circ} \mathrm{C}$. Sections were incubated with anti-FITC antibody conjugated to horseradish peroxidase (1:500, PerkinElmer, Boston, USA) for $1.5 \mathrm{~h}$ at room temperature. A tyramide-biotin amplification system (PerkinElmer) was applied, and then sections were incubated with Alexa 488-conjugated streptavidin (Invitrogen, Eugene, OR, USA) to visualize Kiss 1 signals.

The number of Oprk1- or Kiss1-expressing cells was counted for every fourth ARC section (totally 12-13 sections/animal). Oprk1 mRNA-expressing cells were identified using a bright-field microscope (Olympus BX51, Tokyo, Japan), and images of Kiss 1 mRNA-expressing cells were captured using an LSM 700 laser scanning microscope (Carl Zeiss, Inc. Thornwood, USA). The number of Kiss 1 -expressing cells was counted using ImageJ software (https://imagej.nih.gov/ij/).

\section{Radioimmunoassay (RIA) for LH}

Plasma LH concentration was determined by a doubleantibody radioimmunoassay (RIA) with a rat LH RIA kit provided by the National Hormone and Peptide Program (Baltimore, MD, USA). LH concentrations were expressed in terms of the NIDDK rat LH-RP-3. The least detectable level of the LH assay was $0.16 \mathrm{ng} / \mathrm{mL}$ for 50 $\mu \mathrm{L}$ plasma. The intra-assay coefficient of variation was $6.81 \%$ at $3.29 \mathrm{ng} / \mathrm{mL}$. All samples were measured in one assay, so there was no inter-assay variation.

\section{Statistical analysis}

LH pulses were identified using the PULSAR computer program, as previously described [46]. Statistical differences in LH pulse parameters and the number of Oprk1- or Kiss 1-expressing cells between SAP and DynSAP groups were evaluated by Student's $t$-test using Microsoft Excel software. $P$ values $<0.05$ were considered statistically significant. 
Bregma $-2.5 \mathrm{~mm}$

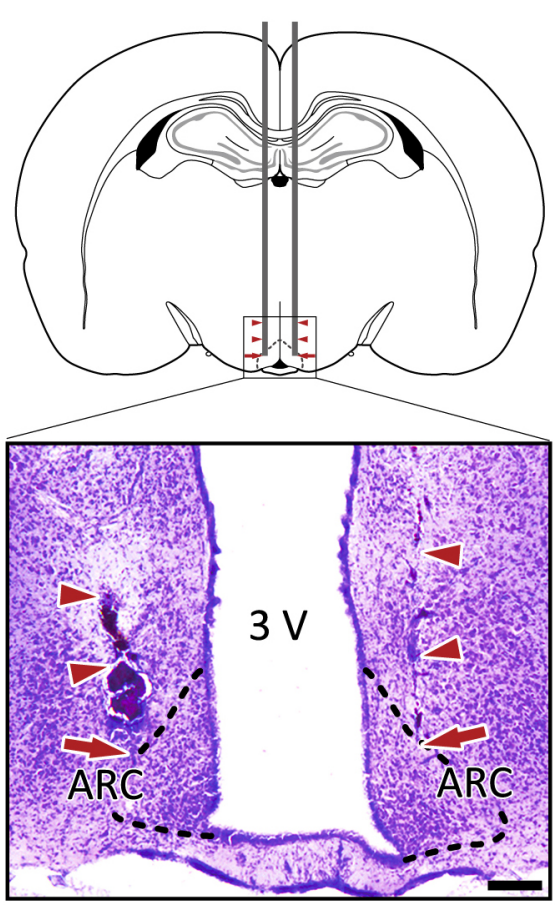

Bregma $-3.6 \mathrm{~mm}$

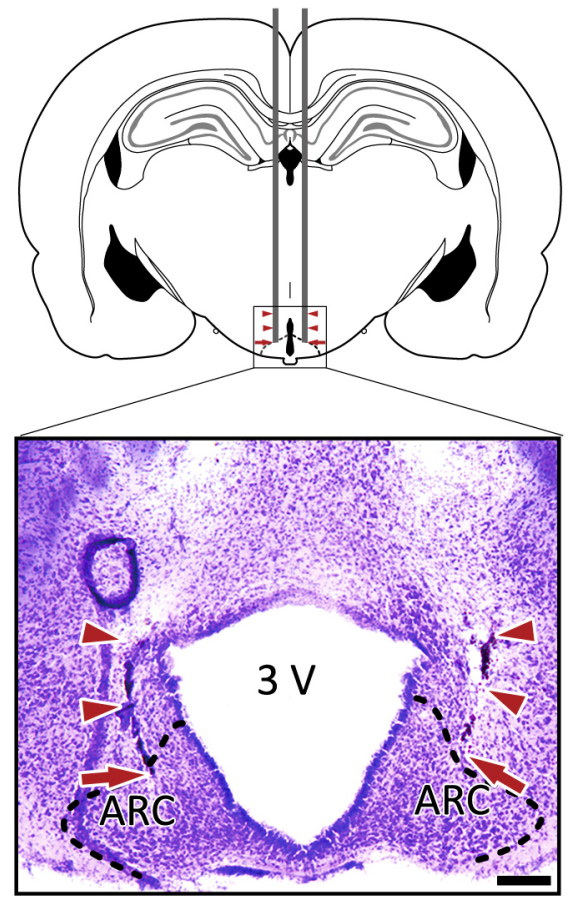

Fig. 1 Verification of injection sites of Dyn-SAP or SAP into the ARC

Schematic illustration indicating the injection site at the anterior (bregma $-2.5 \mathrm{~mm}$ ) and posterior (bregma $-3.6 \mathrm{~mm}$ ) ARC according to the rat brain atlas [42] (top panels). Photomicrographs of Nissl-stained brain sections of the anterior and posterior ARC (bottom panels) in a representative animal. Arrowheads show the trace made by inserting the cannula for intra-ARC injection of Dyn-SAP, and arrows point to the tip of the cannula. Dotted lines indicate the areas of the ARC. Scale bars, $200 \mu \mathrm{m}$.

$3 \mathrm{~V}$, third ventricle; ARC, arcuate nucleus; Dyn-SAP, dynorphin-saporin; SAP, saporin

\section{Results}

\section{Intra-ARC Dyn-SAP treatment specifically reduced the number of Oprk1-expressing cells in the ARC}

The correct placement of intra-ARC injection of DynSAP or SAP was confirmed using Nissl-stained brain sections. The injection sites in all animals were relatively dorsal in the ARC and similar to the sites in a representative animal, whose injection sites in the anterior and posterior parts of the ARC are indicated by arrowheads (Fig. 1). No destruction of brain parenchyma other than the cannula tracts was observed.

A number of Oprkl-expressing cells were detected in the ARC, PVN, and VMH of the SAP-injected control group (Fig. 2A, 2B, and 2C). In the Dyn-SAP-injected group, Oprk1-expressing cells were scattered in the ARC (Fig. 2D), whereas the distribution of Oprkl-expressing cells in the PVN and VMH was similar to that of the SAP-injected control group (Fig. 2E and 2F). Statistical analysis revealed that the number of Oprkl-expressing cells in the ARC of Dyn-SAP-treated group was significantly lower than in the SAP-injected control group $(p<$ 0.05 , Fig. $2 \mathrm{G}$ ). On the other hand, in the PVN and VMH, the numbers of Oprk1-expressing cells were comparable between Dyn-SAP-injected and SAP-injected control groups (Fig. 2G).

\section{Intra-ARC Dyn-SAP treatment enhanced pulsatile LH secretion in female rats}

Plasma LH profiles in representative rats treated with Dyn-SAP or SAP into the ARC are shown in Fig. 3A. The frequency of LH pulses (number of LH pulses in 3-h sampling period) in the Dyn-SAP-injected group was significantly higher than in the SAP-injected control group ( $p<0.01$, Fig. $3 \mathrm{~B})$. The inter-pulse interval was significantly shorter in the Dyn-SAP group than in the SAP group ( $p<0.01$, Fig. 3B). The baseline LH concentration was significantly higher in the Dyn-SAP group than in the SAP group ( $p<0.05$, Fig. 3B). The mean plasma LH level in the Dyn-SAP group tended to be higher than in the SAP group ( $p=0.056$, Fig. 3B), and the mean amplitude of LH pulses in the Dyn-SAP group tended to be lower than in the SAP group ( $p=0.069$, Fig. 3B).

Intra-ARC Dyn-SAP treatment failed to change the number of kisspeptin neurons in the ARC

A number of Kiss 1-expressing cells were found in the 

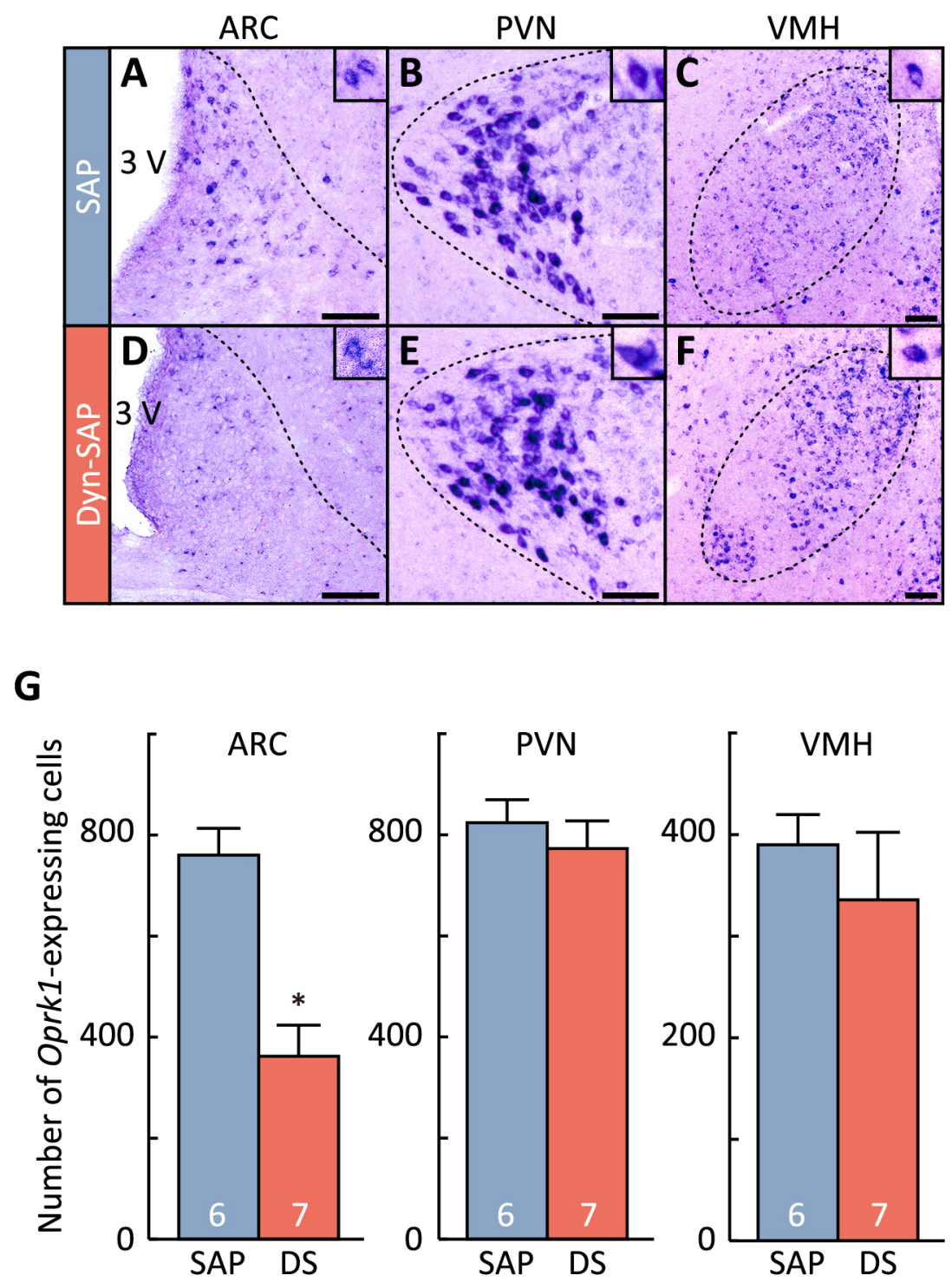

Fig. 2 Effect of intra-ARC Dyn-SAP treatment on Oprk1 expression in the hypothalamus

(A-F) Representative photomicrographs of Oprk1 (kappa-opioid receptor gene)-expressing cells in the ARC (A, D), PVN (B, E), and VMH (C, F) of Dyn-SAP- or SAP-injected animals. Insets: Oprkl-expressing cells at a higher magnification. Scale bars, 100 $\mu \mathrm{m}$. (G) Number of Oprk1-expressing cells in the ARC, PVN, and VMH of Dyn-SAP (DS)- or SAP-injected groups. Values are means $\pm \mathrm{SEM}$. The numbers in each column represent the number of animals in each group. ${ }^{*} p<0.05$, Student's $t$-test.

$3 \mathrm{~V}$, third ventricle; ARC, arcuate nucleus; Dyn-SAP, dynorphin-saporin; PVN, paraventricular hypothalamic nucleus; SAP, saporin; VMH, ventromedial nucleus of the hypothalamus

ARC of both intra-ARC Dyn-SAP- and SAP-injected animals (Fig. 4A). No significant difference was found in the number of Kiss 1-expressing cells in the ARC between the Dyn-SAP and SAP groups (Fig. 4B).

\section{Discussion}

The present study demonstrated that Dyn-KOR signaling in the ARC, at least in part, plays a role in reducing the frequency of $\mathrm{GnRH} / \mathrm{LH}$ pulse generation, because the ARC-specific decline of KOR-expressing cells by local
Dyn-SAP administration into the ARC increased LH pulse frequency and decreased the inter-pulse interval in female rats. The number of Oprkl-expressing cells in the ARC was significantly decreased in Dyn-SAP-treated rats compared to SAP-treated control rats, suggesting that a part of KOR-expressing cells was successfully deleted by the intra-ARC Dyn-SAP injection in vivo. Importantly, the number of Oprk1-expressing cells in the PVN and VMH of Dyn-SAP-treated groups was comparable to that of the SAP-treated control group, demonstrating that deletion of KOR-expressing cells by ARC- 
A

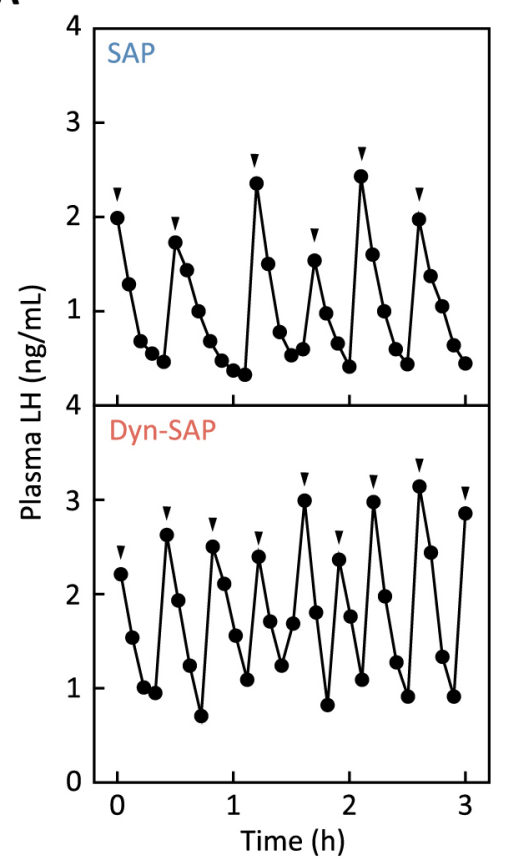

B
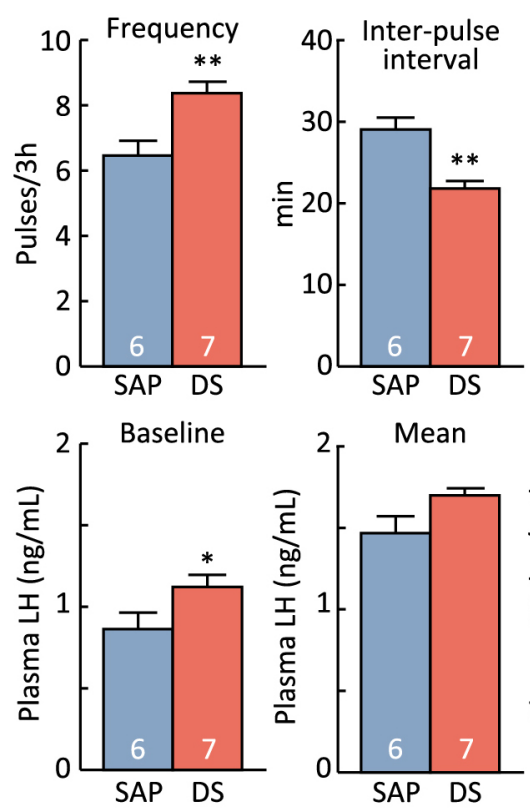
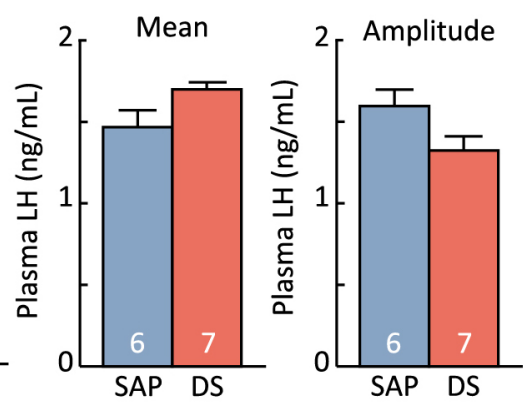

Fig. 3 Effect of intra-ARC Dyn-SAP treatment on pulsatile LH secretion in estrogen-primed ovariectomized rats

(A) Profiles of plasma LH concentration in representative rats injected with Dyn-SAP or SAP into the ARC. Arrowheads indicate the peaks of LH pulses identified by the PULSAR computer program. (B) Number of LH pulses (Frequency), mean inter-pulse interval (Inter-pulse interval), mean baseline LH concentration (Baseline), mean LH concentration (Mean), and mean amplitude of LH pulses (Amplitude) during a $3 \mathrm{~h}$ sampling period in rats treated with Dyn-SAP (DS) or SAP into the ARC. Values are means \pm SEM. The numbers in each column represent the number of animals used in each group. ${ }^{*} p<0.05,{ }^{* *} p<0.01$, Student's $t$-test. ARC, arcuate nucleus; Dyn-SAP, dynorphin-saporin; LH, luteinizing hormone; SAP, saporin

A

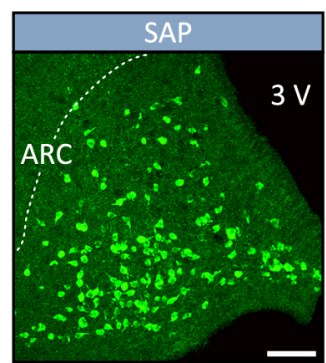

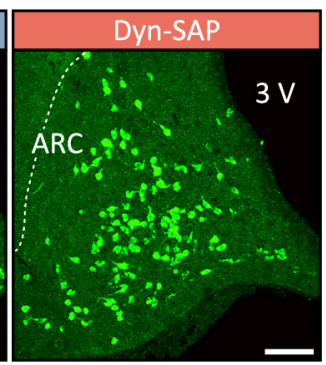

B

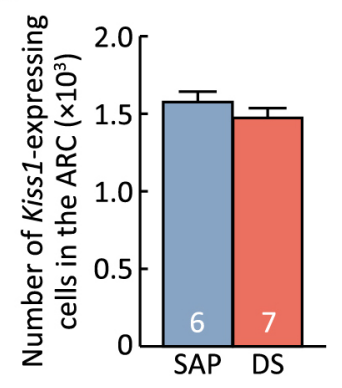

Fig. 4 Effect of intra-ARC Dyn-SAP injection on Kiss 1 expression in the ARC of estrogen-primed ovariectomized rats

(A) Representative photomicrographs of Kiss 1 (kisspeptin gene)-expressing cells in the ARC of intra-ARC Dyn-SAP- or SAPinjected animals. $3 \mathrm{~V}$, third ventricle; scale bars, $100 \mu \mathrm{m}$. (B) Number of Kiss 1 -expressing cells in the ARC of intra-ARC Dyn-SAP (DS) and SAP-injected animals. Values are means \pm SEM. The numbers in each column represent the number of animals in each group.

$3 \mathrm{~V}$, third ventricle; ARC, arcuate nucleus; Dyn-SAP, dynorphin-saporin; SAP, saporin

specific Dyn-SAP injection was limited within the ARC. Taken together, the stimulation of the frequency of LH pulses by Dyn-SAP administration may be due to the specific lesion of KOR-expressing cells in the ARC. A previous study reported that GnRH neurons express KOR in rats [38], implying that Dyn neurons may directly act on GnRH neurons to regulate LH secretion in rats. However, the current study demonstrated that ARCspecific attenuation of Dyn signaling accelerated GnRH/LH pulse frequency, suggesting that KORexpressing cells within the ARC rather than GnRH neurons or other brain regions are involved in the suppression of the firing rate of the $\mathrm{GnRH} / \mathrm{LH}$ pulse generator. 
Interestingly, the number of ARC Kiss1-expressing cells in the Dyn-SAP group was comparable to that of the SAP-treated control group, while Dyn-SAP treatment decreased about half of the number of KOR-expressing cells in the ARC. These results raised the possibility that most KOR-expressing cells deleted by the current DynSAP treatment were non-KNDy KOR neurons. Previous studies reported that $6-20 \%$ of ARC kisspeptin neurons express KOR in mice $[22,40]$ and around $60 \%$ of ARC Kiss1 neurons express KOR in female rats [35]. Importantly, our recent study showed that KOR-expressing cells are abundantly located in the whole ARC of female rats [35]. These studies suggest that some KNDy neurons express KOR, while a number of KOR-expressing cells exist other than KNDy neurons in the ARC. More specifically, the majority of non-kisspeptin KOR-expressing cells are located in the dorsal region of the ARC, while KNDy neurons are located in the ventral part of the nucleus [35]. In this context, the current sites where Dyn-SAP was injected were located in the dorsal region of the ARC. Thus, the present Dyn-SAP treatment may have resulted in the deletion of non-KNDy KOR neurons in the ARC, but not KNDy neurons located in the ventral ARC. The deletion of non-KNDy KOR neurons was thought to lead to the changes in LH secretion observed in the current study. This is largely consistent with a previous study by Ruka et al. [47], which showed that Dyn application reduced the firing of the majority of KNDy neurons in mouse brain slices, despite the low colocalization of KOR in KNDy neurons. Ruka's study and our current findings imply the existence of an indirect Dyn pathway affecting the activity of KNDy neurons. The present study suggests that non-KNDy KOR-expressing cells may play a suppressive role as a modulator for the GnRH pulse generator. In other words, GnRH pulse generation may be controlled by a complicated-neuronal complex composed of KNDy neurons as well as nonKNDy neurons via KOR signaling. Further studies are required to clarify the mechanism mediating Dyn-KOR signaling affecting KNDy neurons and/or non-KNDy neurons to modulate the frequency of $\mathrm{GnRH} / \mathrm{LH}$ pulse generation.

The present results are consistent with those of previous studies showing that ARC-specific agonism/antagonism of KOR inhibited/activated the frequency of $\mathrm{GnRH} / \mathrm{LH}$ pulse generation: intra-ARC administration of U50488, a KOR agonist, decreased LH pulse frequency, and elongated pulse interval in OVX rats primed with negative feedback level of $E_{2}$ [48]; the inter-pulse inter- val of LH pulses was decreased by the microimplant of nor-BNI into the ARC of OVX ewes [12]. It is likely that the agonist or antagonist administered into the ARC may widely affect KOR-expressing neurons located in the $\mathrm{ARC}$, including a part of KNDy neurons as well as nonKNDy neurons in the ARC $[35,38]$. Thus, the total response of ARC KOR-expressing neurons would affect the activity of KNDy neurons and subsequent GnRH/LH pulses. It should be noted that the present study had the advantage of suggesting the involvement of non-KNDy KOR expressing cells in GnRH pulse generation because this approach using Dyn-SAP enabled the irreversible deletion of KOR-expressing cells compared with the approach using KOR agonists/antagonists that only transiently cause KOR agonism/antagonism.

In conclusion, the present study demonstrated that KOR-expressing cells in the ARC have an inhibitory effect on the frequency of $\mathrm{GnRH} / \mathrm{LH}$ pulse generation. Our results also suggest that non-KNDy neurons expressing KOR in the ARC would be involved in mediating the Dyn inhibitory signal to suppress the activity of KNDy neurons and subsequent GnRH/LH release. Further studies are needed to identify the non-KNDy KOR neurons in the ARC and understand the role of DynKOR signaling in regulating GnRH pulse generation as a whole.

\section{Acknowledgments}

We respectfully acknowledge the contributions of our late colleague Professor Kei-ichiro Maeda, who suddenly passed away during the preparation of this manuscript. His leadership and supervision contributed significantly to this work. We thank Prof. Yoshitaka Oka and Dr. Tomomi Karigo at the Graduate School of Sciences, The University of Tokyo for designing the cRNA probe of Oprk1. We are grateful to the National Hormone and Peptide Program for the rat LH RIA kit. The ${ }^{125}$ I-labeled rat LH for RIA was kindly provided by the Laboratory of Animal Production Science at Nagoya University. This work was supported in part by the Grants-in-Aid for Scientific Research (Grant 18H03973 to H. T. and Grant $16 \mathrm{H} 06206$ to F. M.) from the Japanese Ministry of Education, Culture, Sports, Science and Technology.

\section{Disclosure}

None of the authors have any potential conflicts of interest associated with this research. 


\section{References}

1. Wildt L, Hausler A, Marshall G, Hutchison JS, Plant TM, et al. (1981) Frequency and amplitude of gonadotropinreleasing hormone stimulation and gonadotropin secretion in the rhesus monkey. Endocrinology 109: 376-385.

2. Pohl CR, Richardson DW, Hutchison JS, Germak JA, Knobil E (1983) Hypophysiotropic signal frequency and the functioning of the pituitary-ovarian system in the rhesus monkey. Endocrinology 112: 2076-2080.

3. Ohtaki T, Shintani Y, Honda S, Matsumoto H, Hori A, et al. (2001) Metastasis suppressor gene KiSS-1 encodes peptide ligand of a G-protein-coupled receptor. Nature 411: 613-617.

4. Irwig MS, Fraley GS, Smith JT, Acohido BV, Popa SM, et al. (2004) Kisspeptin activation of gonadotropin releasing hormone neurons and regulation of KiSS-1 mRNA in the male rat. Neuroendocrinology 80: 264-272.

5. Kinoshita M, Tsukamura $H$, Adachi $S$, Matsui $H$, Uenoyama Y, et al. (2005) Involvement of central metastin in the regulation of preovulatory luteinizing hormone surge and estrous cyclicity in female rats. Endocrinology 146: 4431-4436.

6. Uenoyama Y, Pheng V, Tsukamura H, Maeda KI (2016) The roles of kisspeptin revisited: inside and outside the hypothalamus. J Reprod Dev 62: 537-545.

7. Ikegami K, Goto T, Nakamura S, Watanabe Y, Sugimoto A, et al. (2020) Conditional kisspeptin neuron-specific Kiss1 knockout with newly generated Kiss1-floxed and Kiss1-Cre mice replicates a hypogonadal phenotype of global Kiss 1 knockout mice. J Reprod Dev 66: 359-367.

8. Ohkura S, Uenoyama Y, Yamada S, Homma T, Takase K, et al. (2009) Physiological role of metastin/kisspeptin in regulating gonadotropin-releasing hormone $(\mathrm{GnRH})$ secretion in female rats. Peptides 30: 49-56.

9. Lehman MN, Coolen LM, Goodman RL (2010) Minireview: kisspeptin/neurokinin B/dynorphin (KNDy) cells of the arcuate nucleus: a central node in the control of gonadotropin-releasing hormone secretion. Endocrinology 151: 3479-3489.

10. Smith JT, Li Q, Yap KS, Shahab M, Roseweir AK, et al. (2011) Kisspeptin is essential for the full preovulatory LH surge and stimulates GnRH release from the isolated ovine median eminence. Endocrinology 152: 1001-1012.

11. Naniwa Y, Nakatsukasa K, Setsuda S, Oishi S, Fujii N, et al. (2013) Effects of full-length kisspeptin administration on follicular development in Japanese Black beef cows. $J$ Reprod Dev 59: 588-594.

12. Goodman RL, Hileman SM, Nestor CC, Porter KL, Connors JM, et al. (2013) Kisspeptin, neurokinin B, and dynorphin act in the arcuate nucleus to control activity of the $\mathrm{GnRH}$ pulse generator in ewes. Endocrinology 154: 4259-4269.

13. Plant TM, Ramaswamy S (2009) Kisspeptin and the regulation of the hypothalamic-pituitary-gonadal axis in the rhesus monkey (Macaca mulatta). Peptides 30: 67-75.
14. Guerriero KA, Keen KL, Millar RP, Terasawa E (2012) Developmental changes in GnRH release in response to kisspeptin agonist and antagonist in female rhesus monkeys (Macaca mulatta): implication for the mechanism of puberty. Endocrinology 153: 825-836.

15. Watanabe Y, Uenoyama Y, Suzuki J, Takase K, Suetomi Y, et al. (2014) Oestrogen-induced activation of preoptic kisspeptin neurones may be involved in the luteinising hormone surge in male and female Japanese monkeys. $J$ Neuroendocrinol 26: 909-917.

16. Seminara SB, Messager S, Chatzidaki EE, Thresher RR, Acierno JS Jr, et al. (2003) The GPR54 gene as a regulator of puberty. N Engl J Med 349: 1614-1627.

17. de Roux N, Genin E, Carel JC, Matsuda F, Chaussain JL, et al. (2003) Hypogonadotropic hypogonadism due to loss of function of the KiSS1-derived peptide receptor GPR54. Proc Natl Acad Sci U S A 100: 10972-10976.

18. Uenoyama $Y$, Nakamura S, Hayakawa $Y$, Ikegami K, Watanabe Y, et al. (2015) Lack of pulse and surge modes and glutamatergic stimulation of LH release in Kiss 1 knockout rats. J Neuroendocrinol 27: 187-197.

19. Burke MC, Letts PA, Krajewski SJ, Rance NE (2006) Coexpression of dynorphin and neurokinin B immunoreactivity in the rat hypothalamus: morphologic evidence of interrelated function within the arcuate nucleus. J Comp Neurol 498: 712-726.

20. True C, Kirigiti M, Ciofi P, Grove KL, Smith MS (2011) Characterisation of arcuate nucleus kisspeptin/neurokinin $\mathrm{B}$ neuronal projections and regulation during lactation in the rat. J Neuroendocrinol 23: 52-64.

21. Murakawa H, Iwata K, Takeshita T, Ozawa H (2016) Immunoelectron microscopic observation of the subcellular localization of kisspeptin, neurokinin B and dynorphin A in KNDy neurons in the arcuate nucleus of the female rat. Neurosci Lett 612: 161-166.

22. Navarro VM, Gottsch ML, Chavkin C, Okamura H, Clifton DK, et al. (2009) Regulation of gonadotropinreleasing hormone secretion by kisspeptin/dynorphin/ neurokinin B neurons in the arcuate nucleus of the mouse. J Neurosci 29: 11859-11866.

23. Nakamura S, Ito Y, Yamamoto K, Takahashi C, Dai M, et al. (2017) SB223412, a neurokinin-3 receptor-selective antagonist, suppresses testosterone secretion in male guinea pigs. Theriogenology 102: 183-189.

24. Goodman RL, Lehman MN, Smith JT, Coolen LM, de Oliveira CV, et al. (2007) Kisspeptin neurons in the arcuate nucleus of the ewe express both dynorphin A and neurokinin B. Endocrinology 148: 5752-5760.

25. Wakabayashi Y, Nakada T, Murata K, Ohkura S, Mogi K, et al. (2010) Neurokinin B and dynorphin A in kisspeptin neurons of the arcuate nucleus participate in generation of periodic oscillation of neural activity driving pulsatile gonadotropin-releasing hormone secretion in the goat. $J$ Neurosci 30: 3124-3132. 
26. Maeda K, Ohkura S, Uenoyama Y, Wakabayashi Y, Oka Y, et al. (2010) Neurobiological mechanisms underlying GnRH pulse generation by the hypothalamus. Brain Res 1364: 103-115.

27. Okamura H, Tsukamura H, Ohkura S, Uenoyama Y, Wakabayashi Y, et al. (2013) Kisspeptin and GnRH pulse generation. Adv Exp Med Biol 784: 297-323.

28. Clarkson J, Han SY, Piet R, McLennan T, Kane GM, et al. (2017) Definition of the hypothalamic GnRH pulse generator in mice. Proc Natl Acad Sci U S A 114: E10216-E10223.

29. Herbison AE (2018) The gonadotropin-releasing hormone pulse generator. Endocrinology 159: 3723-3736.

30. Minabe S, Nakamura S, Fukushima E, Sato M, Ikegami K, et al. (2020) Inducible Kiss 1 knockdown in the hypothalamic arcuate nucleus suppressed pulsatile secretion of luteinizing hormone in male mice. J Reprod Dev 66: 369-375.

31. Nagae M, Uenoyama Y, Okamoto S, Tsuchida H, Ikegami $\mathrm{K}$, et al. (2021) Direct evidence that KNDy neurons maintain gonadotropin pulses and folliculogenesis as the $\mathrm{GnRH}$ pulse generator. Proc Natl Acad Sci U S A 118: e2009156118.

32. Mostari P, Ieda N, Deura C, Minabe S, Yamada S, et al. (2013) dynorphin-kappa opioid receptor signaling partly mediates estrogen negative feedback effect on LH pulses in female rats. J Reprod Dev 59: 266-272.

33. Khachaturian H, Watson SJ, Lewis ME, Coy D, Goldstein A, et al. (1982) Dynorphin immunocytochemistry in the rat central nervous system. Peptides 3: 941-954.

34. Fallon JH, Leslie FM (1986) Distribution of dynorphin and enkephalin peptides in the rat brain. J Comp Neurol 249: 293-336.

35. Tsuchida H, Mostari P, Yamada K, Miyazaki S, Enomoto Y, et al. (2020) Paraventricular dynorphin A neurons mediate LH pulse suppression induced by hindbrain glucoprivation in female rats. Endocrinology 161: bqaa161.

36. Mansour A, Fox CA, Burke S, Meng F, Thompson RC, et al. (1994) $\mathrm{Mu}$, delta, and kappa opioid receptor mRNA expression in the rat CNS: an in situ hybridization study. $J$ Comp Neurol 350: 412-438.

37. Chen C, Willhouse AH, Huang P, Ko N, Wang Y, et al. (2020) Characterization of a knock-in mouse line expressing a fusion protein of kappa opioid receptor conjugated with tdTomato: 3-dimensional brain imaging via CLARITY. eNeuro 7: ENEURO.0028-20.2020.

38. Weems PW, Witty CF, Amstalden M, Coolen LM,
Goodman RL, et al. (2016) kappa-Opioid receptor is colocalized in GnRH and KNDy cells in the female ovine and rat brain. Endocrinology 157: 2367-2379.

39. de Croft S, Boehm U, Herbison AE (2013) Neurokinin B activates arcuate kisspeptin neurons through multiple tachykinin receptors in the male mouse. Endocrinology 154: 2750-2760.

40. Navarro VM, Castellano JM, McConkey SM, Pineda R, Ruiz-Pino F, et al. (2011) Interactions between kisspeptin and neurokinin B in the control of GnRH secretion in the female rat. Am J Physiol Endocrinol Met 300: E202E210.

41. Bergamaschi G, Perfetti V, Tonon L, Novella A, Lucotti C, et al. (1996) Saporin, a ribosome-inactivating protein used to prepare immunotoxins, induces cell death via apoptosis. Br J Haematol 93: 789-794.

42. Paxinos G, Watson C (2007) The Rat Brain in Stereotaxic Coordinates (6th). Academic Press, Massachusetts, USA.

43. Mittelman-Smith MA, Williams H, Krajewski-Hall SJ, Lai J, Ciofi P, et al. (2012) Arcuate kisspeptin/neurokinin B/ dynorphin (KNDy) neurons mediate the estrogen suppression of gonadotropin secretion and body weight. Endocrinology 153: 2800-2812.

44. Cagampang FR, Maeda KI, Tsukamura H, Ohkura S, Ota K (1991) Involvement of ovarian steroids and endogenous opioids in the fasting-induced suppression of pulsatile $\mathrm{LH}$ release in ovariectomized rats. $J$ Endocrinol 129: 321328.

45. Minabe S, Ieda N, Watanabe Y, Inoue N, Uenoyama Y, et al. (2017) Long-term neonatal estrogen exposure causes irreversible inhibition of LH pulses by suppressing arcuate kisspeptin expression via estrogen receptors alpha and beta in female rodents. Endocrinology 158: 2918-2929.

46. Merriam GR, Wachter KW (1982) Algorithms for the study of episodic hormone secretion. Am J Physiol 243: E310-E318.

47. Ruka KA, Burger LL, Moenter SM (2013) Regulation of arcuate neurons coexpressing kisspeptin, neurokinin B, and dynorphin by modulators of neurokinin 3 and kappaopioid receptors in adult male mice. Endocrinology 154: 2761-2771.

48. Grachev P, Li XF, Kinsey-Jones JS, di Domenico AL, Millar RP, et al. (2012) Suppression of the GnRH pulse generator by neurokinin B involves a kappa-opioid receptor-dependent mechanism. Endocrinology 153: 4894-4904. 